\title{
Rollerblading in children: the Edinburgh experience
}

\author{
David McGrath, Thomas F Beattie
}

\begin{abstract}
Objective-To determine the incidence and severity of injuries sustained by children who present to an accident and emergency (A\&E) department following rollerblading accidents.
\end{abstract}

Design-A prospective case-control study. Setting-The A\&E department of a city centre paediatric teaching hospital.

Methods-Data were collected on a specially designed proforma on each child presenting with an injury sustained while rollerblading. The injury severity score was calculated for each patient and details were taken of the length of admission or outpatient follow up where appropriate. Results-Seventy four children (37 male; 37 female) presented with injuries over a three month period. The age range was 6-13 years in both groups. Half the injuries occurred at weekends. Fractures $(n=37)$ and soft tissue injuries $(n=28)$ were the most prevalent; $89 \%$ of injuries involved the limbs. Sixty eight children (92\%) required treatment in A\&E. Four (3\%) were admitted to hospital and required operative procedures under general anaesthetic. The injury severity score ranged from 1 to 9 with a mean of 2.8 . The length of hospital stay for admissions was 1-3 days; 47 children required follow up in the outpatient department (1-3 visits). Average length of outpatient contact was 18 days.

Conclusions-This study shows a greater incidence of rollerblading injuries than has been reported elsewhere. No figures are at present available for the United Kingdom as a whole.

(F Accid Emerg Med 1996;13:354-355)

Key terms: rollerblading; injuries

"In-line skating" or "rollerblading" has increased in popularity in the United States since 1987. In Edinburgh we now regularly see children presenting to accident and emergency (A\&E) with injuries sustained while rollerblading. Because there is a perception that these children have a high incidence of fractures and other serious injuries we undertook this prospective study to determine the incidence and severity of injuries sustained.

\section{Methods}

PATIENTS

All children attending $A \& E$ following a rollerblading injury in a 12 week period were included. Our department is situated in the Royal Hospital for Sick Children and we see all children in Edinburgh who present with accidents or emergencies. Twenty eight thousand new patients attended the department last year.

\section{STUDY PROCEDURE}

Each patient presenting following an injury sustained while rollerblading had the case notes flagged by the triage nurse. Data were collected prospectively on a proforma designed to gather all relevant information. Details of any treatment in the department or in theatre, if the child was admitted, were noted and documented after discharge. The injury severity score was calculated for each patient and details were taken of length of admission or out patient follow up where appropriate.

\section{Results}

The results are shown in the table. Seventy four children ( 37 boys and 37 girls) presented with injuries over a 12 week period. The age range was from six to 13 years (mean 10 years). Forty eight per cent of the injuries occurred at the weekend. Fractures $(n=37)$ and soft tissue injuries $(n=28)$ were the most prevalent, with $89 \%$ of the injuries involving the limbs. Sixty eight children $(92 \%)$ required treatment in $A \& E$. The injury severity scores ranged from 1 to 9 with a mean of 2.8 . Twenty nine children $(39 \%)$ required immobilisation in a cast. Six (8\%) had wound closure in the department. Four (5\%) underwent manipulation under anaesthetic in theatre. The length of hospital stay for these admissions ranged from one to three days (mean two days). Forty seven children required follow up at the outpatient department (range one to three visits, mean 1.5 visits). Mean length of outpatient contact was 18 days, with a range of three to 40 days.

\section{Discussion}

Rollerblading, or wheels in line roller-skating, was formally introduced in 1980 in the United States by the Rollerblade Company Inc. ${ }^{1}$ Initially these blades consisted of three wheels 
Type of injury and distribution of fractures sustained by children while rollerblading

\begin{tabular}{llll}
\hline & Male & Female & Total \\
\hline Soft tissue injury & 11 & 17 & 28 \\
Laceration & 6 & 1 & 7 \\
Head injury & 2 & 0 & 2 \\
Fractures & 18 & 19 & 37 \\
Simple forearm & 9 & 12 & 21 \\
Compound forearm & 2 & 0 & 2 \\
Humerus & 1 & 1 & 2 \\
Hand & 4 & 5 & 9 \\
Other & 2 & 1 & 3 \\
\hline
\end{tabular}

which were fixed to the base of ice skating boots for use in summer training by ice hockey teams. By 1987 the company altered its marketing strategy by customising the blades in fashionable neon colours and donating hundreds of pairs to skate hire shops on beaches in California, and the rollerblade craze was born. By 1990, 700000 Americans had purchased blades and this figure had risen to an estimated 9.4 million by last year. Experienced rollerbladers can achieve speeds of $45 \mathrm{mph}$ on the flat, and the world speed record is $75 \mathrm{mph} .^{2}$ It is anticipated that United Kingdom growth will mirror the American experience.

Published reports on injuries associated with rollerblading are sparse, but statistical reviews using the National Electronic Injury Surveillance System (NEISS ) have been carried out in the United States. ${ }^{3}$ Their findings for all ages (5-71 years) revealed a similar frequency of fractures and dislocations to our study, which was confined to children aged 6-13.

Our figures suggest the need for protective accessories during rollerblading. As $28 \%$ of the children in our series had sustained wrist fractures, there is a strong case for advising the use of wrist supports. Helmets have previously been recommended for this type of activity. ${ }^{4}$ With regard to knee and elbow pads, we saw one patient with a fractured patella and one with a supracondylar fracture, and it is possible that these injuries could have been prevented if padding had been in use. Abrasions, to our surprise, did not feature as a presenting complaint from any of our patients. There were no deaths in our series, unlike a US study ${ }^{5}$ which reported that a remarkable seven out of 444 bladers who sustained injury subsequently died as a result of those injuries. The most common cause of death was involvement in a road traffic accident when out of control. None of our patients presented with skull fractures, but these have been reported in other series. ${ }^{6}$

We recommended the use of wrist protection and helmets to all children in this study. Parental cooperation is essential, although when one sees a child with a deformed forearm actually rollerblade into the department while accompanied by a parent, as we have seen, it may be that the safety message should be aimed directly at the children. In Canada, suggestions from the University of Ottawa include a training period emphasising survival skills such as stopping and manoeuvring, protective wrist guards and helmets, and the abolition of on-road skating. Last autumn a cyclist died following a collision with a rollerblader in Hyde Park and with the incidence of $A \& E$ attendances likely to spiral it seems only a matter of time before a child will present to our department with major or life threatening injuries following a road traffic accident while rollerblading out of control.

\section{CONCLUSION}

Our study reveals a higher incidence of visits to $A \& E$ than we had suspected. The virtual absence of protective measures almost certainly accounts for the high percentage of fractures and other serious injuries. The morbidity associated with these injuries is shown by the mean length of outpatient contact. This has cost implications for the service and for the families involved.

Our thanks go to Mrs Elaine Lord for assistance in the preparation of this paper and also to the nursing and medical staff of the Accident and Emergency Department of the Royal Hospital for Sick Children.

1 Gross DM. Zipping along in asphalt heaven. An upstart Minnesota company, Rollerblade, streaks to success. Time Magazine 1990;136:56.

2 Berrington L Darch M. The Times 10 July 1995.

3 Schieber RA, Branch-Dorsey CM, Ryan GW. Comparison Schieber RA, Branch-Dorsey CM, Ryan GW. Comparison of in-line skating injuries with rollerska
ing injuries. $¥ A M A$ 1994;271:1856-8.

4 Thompson RS, Rivara FP, Thompson DC. A case control Thompson RS, Rivara FP, Thompson DC. A case control
study of the effectiveness of bicycle safety helmets. $N$ Engl $f$ study of the effectiveness

Med 1989;320:1361-7.
5 Calle C, Eaton RG. Wheels-in-line roller skating injuries. $\mathcal{F}$ Trauma 1993;35:946-51.

6 Weinberger DG, Selesnick SH. Roller blade falls-a new cause of temporal bone fractures. $\mathcal{F}$ Trauma $1994 ; 37: 500-3$. 